\title{
Conquering Corruption: An Evaluation of the European Union's Efforts in Ukraine
}

\author{
Callie Burklew \\ University of Florida
}

Faculty mentor: Amie Kreppel, Department of Political Science

\begin{abstract}
Even after the Revolution of 2014, reducing the level of corruption within Ukraine has remained a challenging goal. Ukraine's border conflict makes adequately addressing the roots of its corruption without unduly undermining state capacity especially challenging. Despite this delicate situation, the establishment of a stable, lawful, and democratic Ukraine is of vital importance to the European Union given its geopolitical significance. Certain arguments in the literature provide a possible solution to reducing corruption by expanding civil society and thus improving levels of generalized social trust and social accountability. Accordingly, this paper explores the extent and effect of the EU's support for civil society and anti-corruption efforts in Ukraine. It also examines any counterproductive results from this assistance, such as unnecessarily fueling public cynicism and distrust. With the limited data available, the preliminary findings of this paper suggest that while the factors influencing corruption are complex and interrelated, civil society and anti-corruption efforts may increase aid effectiveness. For more conclusive findings in the future, it will be necessary for more comprehensive and consistent data collection by the European Union and civil society organizations in Ukraine.
\end{abstract}

\section{Introduction}

In 2013, Ukraine came within inches of an associational agreement with the European Union (EU), but instead faced a revolution, government collapse, and the loss of its sovereign territory. In the ensuing years, the eastern portion of Ukraine has festered with violence and economically stagnated. Within this broadly unsettled context, Ukraine must deal with another impediment to its democratization and growth - a culture of corruption propelled by cronyism, collusion, bribery, and extortion (Kiev International Institute of Sociology, 2015).

Fortunately, Ukraine is not alone in its fight against corruption. Since 2014, the EU has provided billions in grants and loans to support Ukraine since 1991 (European External Action Service, 2019). Aside from humanitarian concerns, the EU has economic, political, and, most significantly, security motivations for assisting Ukraine. If Ukraine cannot stem its corruption, it could destabilize the region with yet another revolution or more fully succumb to Russian 
influence, which would have massive implications for international relations and the potential strength of an unfriendly Russian state (Schmidt, 2007).

The EU has numerous reasons to establish a stable and democratic Ukraine, devoid of corruption. However, the path to reducing corruption is elusive, especially without excessively fueling citizen discontent. Anti-corruption initiatives' continual exposure of corrupt practices can erode confidence in public institutions, potentially leading to destabilizing populist pushback or an overall disillusionment with democracy (Andersson \& Heywood, 2006). Additionally, the determinants, and corresponding anti-corruption strategies, are heavily debated in the literature. While many elements contribute to effectively controlling corruption, this paper focuses on a more recently emphasized component - a robust and publicly engaged civil society.

The importance of civil society within an anti-corruption context is two-fold. First, civil society organizations (CSO) help connect individuals and build positive societal values and trust, which can help combat a collective action problem that leads to complacence and even acceptance of corruption. Second, in what is usually defined as social accountability, CSOs themselves can act as an accountability mechanism, applying pressure on local and national governments through activities like policy advocacy or public service monitoring.

Currently, there is a lack of empirical research on the connection between anti-corruption and civil society in post-Soviet states (Bhargava, Cutler, Ritchie, 2011). Also, the conceptual analysis of how collective action, voice, and accountability contribute to, or potentially detract from, anticorruption efforts is still limited (UK Department for International Development [DFID], 2015, p. 16; Schmidt, 2007). Lastly, analysis specific to EU assistance to Ukraine remains understudied (Wolczuk \& Žeruolis, 2018). To supplement these literature gaps, this research analyzes the character and effects of EU's foreign assistance to Ukraine in the $21^{\text {st }}$ century. More specifically, this analysis attempts to determine the extent of EU aid for civil society, and whether this aid is achieving its intended purpose, most directly via civic engagement and the strengthening of civil society, and indirectly by reducing corruption. Given the potential of adverse consequences of foreign aid discussed above, this research will also explore potentially counterproductive effects such as excessive distrust or a negative impact on generalized trust. 


\section{Corruption}

\section{Determinants of Corruption: The Problem}

When addressing corruption, external practitioners focus on either formal or informal institutions. Those that focus on formal institutions conduct projects that institutionally reform areas like public financial management or civil service. These anti-corruption projects include new laws or codes of ethics, which supposedly reduce opportunity for corruption by shaping constraints and incentives. However, in recent decades, this technical approach has experienced a wide implementation gap between the reform expectation and results (Bhargava et al., 2011). This suggests that while copying and pasting laws and reforms may be straightforward, erasing historical mentalities and illicit networks is more complex and norm laden.

If an exclusive focus on formal institutions is insufficient, as experience suggests, then informal institutions, cultural norms, values, and ethics, must be considered. This approach does not dismiss the importance of political and state institutions. Instead it brings norms and values into the fold of variables in consideration by suggesting a collective action problem - a problem rooted in the need for better normative constraints (Mungiu-Pippidi 2013; DFID, 2015).

Several interrelated issues compel the collective action problem (Zapata, 2018). The first is a weak and unengaged civil society driven by public apathy and cynicism. This along with the perceived high transactions costs of not being corrupt, lead to a tendency towards freeriding (Zapata, 2018). This cultural reality limits the strength and effectiveness of civil society, without which individuals cannot effectively monitor and mitigate corruption.

Another component of the collective action problem is generalized trust, or trust in the unknown person, which can be improved upon by a stronger civil society (Mungiu-Pippidi, 2013). Former communist nations generally have low levels of both social and institutional trust (Letki \& Evans, 2005). Ukraine is no exception. Unfortunately, low levels of trust relate to corruption, because the more distrustful someone becomes, the more likely they are to tolerate corruption, if not actively be corrupt (DFID, 2015). If a core problem of corrupt societies, including Ukraine, is a collective action problem as this evidence suggests, what activities can address this problem?

\section{Citizens and Corruption: A Solution}

Emphasis of civil society, a community of citizens linked by common interests and collective activity, within the scope of anti-corruption was partially in reaction to the shortcomings of the 
international anti-corruption movement, which, until more recently, focused mostly on government-oriented formal reforms (Marín, 2016). Unsurprisingly, many of the corrupted central governments did not have the incentive or political will to make good on such international assistance. Not only did this assistance have nominal to no effects, but some scholars argue that donor support may have sustained corruption (DFID, 2015).

Therefore, major adjustments in strategy were in order, and shortly after the turn of the century, international development institutions began to stress the importance of civil society within the anti-corruption process, thereby acknowledging the collective action problem (Marín, 2016, Mungiu-Pippidi, 2013). By addressing the collective action problem through support to civil society, generalized trust could be increased by bonds forged through community activity, and thus reducing the shared expectations that other actors are self-maximizers, or corrupt, which then incentivizes people to not be corrupt (DFID, 2015). Second, if the collective action problem is mitigated, then citizens will be enabled to effect change by keeping public actors accountable, a concept known as social accountability (SAcc). Anti-corruption SAcc activities include, but are not limited to, institutionalized participatory processes, social audits, investigative journalism, awareness-raising, and open data platforms (Marín, 2016).

\section{The European Union, Corruption, and Ukraine}

In light of the complicated conversation surrounding corruption, how can the EU best shape its aid programs to reduce corruption and support a stable and democratic Ukraine? This paper argues that aid programs for civil society will greatly abet the general anti-corruption movement in Ukraine, because as discussed in the determinants section, the more traditional, technical anticorruption approach, which focuses on formal institutions, ignores the citizen's role in anticorruption. Whereas the collective action approach considers the cultural component of corruption, and is therefore more applicable in the case of Ukraine, which has had widespread corruption since the fall of communism (DFID, 2015).

The EU has already made positive modifications to its development strategy as to the above points, by reducing its budgetary and purely technical support to the Ukrainian government that was effectively squandered by Ukraine's weak institutional capacity. It has also begun to incorporate the contextuality of the local setting, and cooperate more with civil society (Wolczuk $\&$ Žeruolis, 2018, p. 17). The quantitative research attempts to determine the extent and the 
effectiveness of the latter most change in addition to any potentially counterproductive effects these changes may have.

Beyond simply reducing corruption, the EU must consider the broader context of Ukraine as a potentially volatile, geopolitical state within its neighborhood. If levels of generalized social trust and trust in government are negatively impacted by EU aid, this could weaken the legitimacy and capacity of Ukraine's government, making it vulnerable to Russian influence, populism, and destabilization (Andersson \& Heywood, 2006). If this is the case, then the EU should be mindful of how its assistance programs affect social trust.

\section{Hypotheses}

This research categorizes EU aid to quantitatively analyze if it has achieved its intended purpose, most directly by strengthening civil society, and indirectly by reducing corruption. Additionally, this research checks for counterproductive effects of the EU's aid, through levels of generalized social trust, levels of trust in government, and public cynicism. In answer to these questions, I have developed several hypotheses as follow:

Hypothesis 1. EU aid targeted at civil society will strengthen civil society.

Hypothesis 2. EU aid targeted at civil society will reduce corruption.

Hypothesis 3.1. EU aid targeted at civil society will marginally increase levels of generalized social trust

Hypothesis 3.2. EU aid will marginally increase levels of distrust in the government's institutions.

\section{Methodology}

Gathering data for this project has proven difficult due to the lack of three factors corruption indicators, a comprehensive set of aid data from the EU, and consistent, longitudinal, social data for Ukraine. However, I did code the EU's aid data on a project basis as either targeted at civil society or not, as determined by the available project descriptions and documents. Additionally, I conducted nonparametric bivariate correlation analyses, because the limited nature of the available data does not allow for a parametric regression analysis as it would not reach an asymptotic confidence level. I chose Kendall's tau-b $\left(\tau_{\mathrm{b}}\right)$ as my nonparametric correlation coefficient, because my data meets its two assumptions - first, that the data must be at least ordinal or interval, and second, that there must be a likely monotonic relationship (which is depicted in the graphs below; Laerd Statistics, 2018). Additionally, this 
test is recommended for data of "a small sample size with many tied ranks," which reflects my dataset (Laerd Statistics, 2018). I also display charts in each of the dependent variable sections that display sets of pairwise correlation analyses, which show the independent variable, civil society aid, the dependent variable, and other covariate variables that could be alternate causal factors.

\section{Independent Variable}

European Union Aid Data Source. Surprisingly, EU aid data was particularly difficult to track down, because there is no single database which contains up-to-date, project details, as its aid 'portal,' is actually sourced from other databases, and thus is redundant and inconsistent. After numerous information enquiries and emails, I was directed by the Europe Direct Contact Center to the International Aid Transparency Initiative (n.d.), which has published EU aid data on a project basis with sufficient descriptors from 2001 through 2016.

European Aid Data Coding. I categorized all 913 projects as having civil society purposes with a 'no', denoted by a 0 , or a 'yes', denoted by a 1 .

The following words and concepts were important in designating a project as a 1 for civil society, and are derived from activities that position the citizens in the public sphere and which are empowering to civil society:

- community, awareness-raising, non-governmental organizations (NGO), civil society organizations (CSO), information society, building local capacity, advocacy, civil society dialogue and democratic discourse, journalism, free media

\section{Dependent Variables}

Civil Society. To measure the robustness and capacity of civil society in context of my hypotheses, I use USAID's CSO Sustainability Index (CSOsustain) as it measures the strength and viability of the civil society sector. Additionally, I use a dimension of this index, CSO advocacy (CSOadvocacy), as another indicator because it most closely captures the concept of social accountability, an output of a robust civil society, which is critical to anti-corruption.

Corruption. The most prevalent and feasible form of estimating corruption is through surveys. Transparency International's and the World Bank Groups's well-known Corruption Perceptions Index (CPI) and Worldwide Governance Index (WGI) are both international corruption indexes based on perceptions, and thus will be used to measure levels of corruption. 
Social Trust. To evaluate any unintended consequences of EU aid, I found social data on generalized social trust and trust in governmental institutions. The Ukrainian Society Journal has produced a reasonably consistent survey that monitors trust in various governmental institutions and, more sporadically, CSOs in Ukraine, whilst the Kiev International Institute of Sociology has also conducted surveys with the same question. Between the two of these, I have compiled survey data for the following question:

- To what extent do you trust the following social institutions: city council, civil society organizations, Verkhovna Rada (The Ukrainian Parliament), law agencies

The first two measures include institutions with whom the public will frequently interact, and thus serve as reasonably proxies for generalized trust. The second two measures capture perspectives of major state institutions important in the corruption conversation as both abusers and reformers. Perceptions of these institutions could be influenced by anti-corruption crusades, which, if excessive, could counterproductively diminish the public's belief in the Ukrainian government and thus harm public engagement and sense of self-determination.

\section{Data and Analysis}

EU Aid. Figures 1 and 2 depict categorized EU aid in dollars, for which the source data does not indicate if it is inflation adjusted or not and thus is assumed, and the percent of civil society (CS) aid per year. EU aid trended upwards over the entire period, but dramatically so in 2014, following the revolution. An interesting observation is that in 2014, EU aid targeted at the CS increased dramatically not only in absolute terms, but as a percent of total aid, from $10 \%$ and under to around $50 \%$.

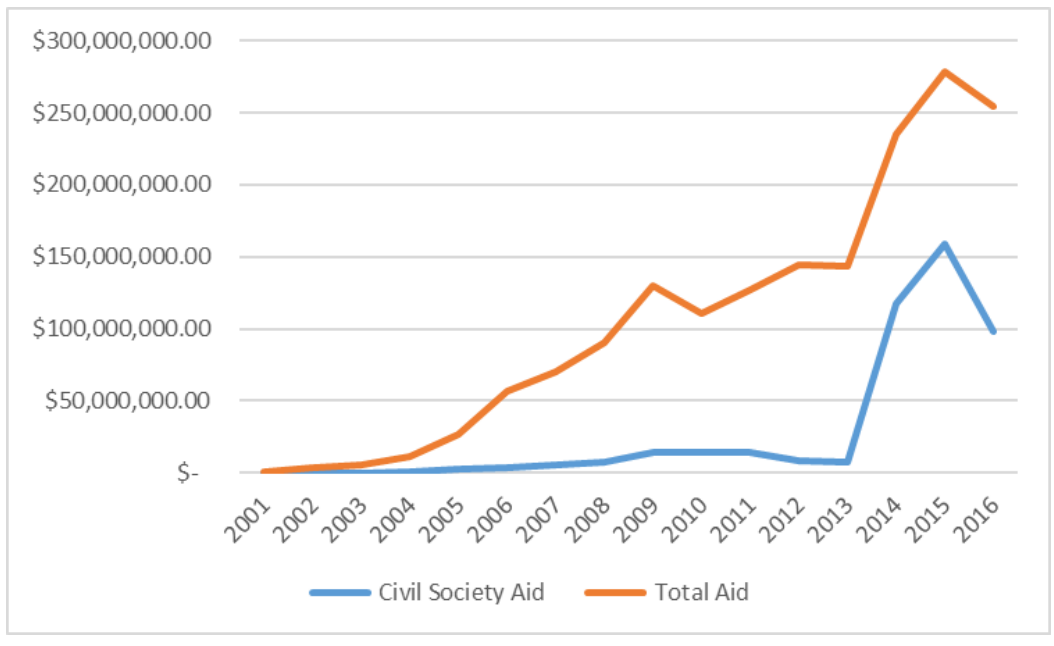

Figure 1: EU and CS Aid in Dollars 


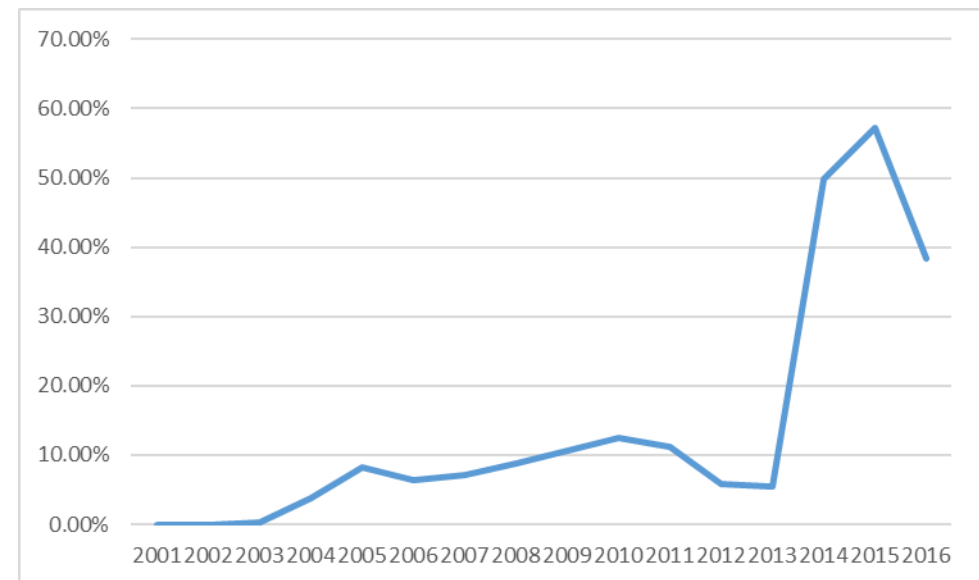

Figure 2: CS Aid in Percent

EU Aid and Civil Society. Figure 3 shows a downward trend of the CSO Sustainability Index which implies improvement in the social and political environment for CSOs. This figure shows a likely monotonic relationship, since EU civil society aid has gone up over time and civil society has strengthened. Further, a Kendall's tau-b correlation was run to determine the relationship between these factors (Figure 4). There was a strong correlation between CS aid and both civil society strength indicators (CSOsutain $\tau_{\mathrm{b}}=.823, p=.000$; CSOadvocacy $\tau_{\mathrm{b}}=.814, p=$ .000). Both were also statistically significant at the .05 level (two-tailed). The pairwise correlations offers no stronger correlations with the civil society strength indicators, though the trust in law agencies variable also has a strong correlation with the civil soceity strength indicators, thus could be an alternate predictive variable. This data suggests Hypothesis 1, that EU aid targeted at civil society will strengthen civil society, could possibly be correct.

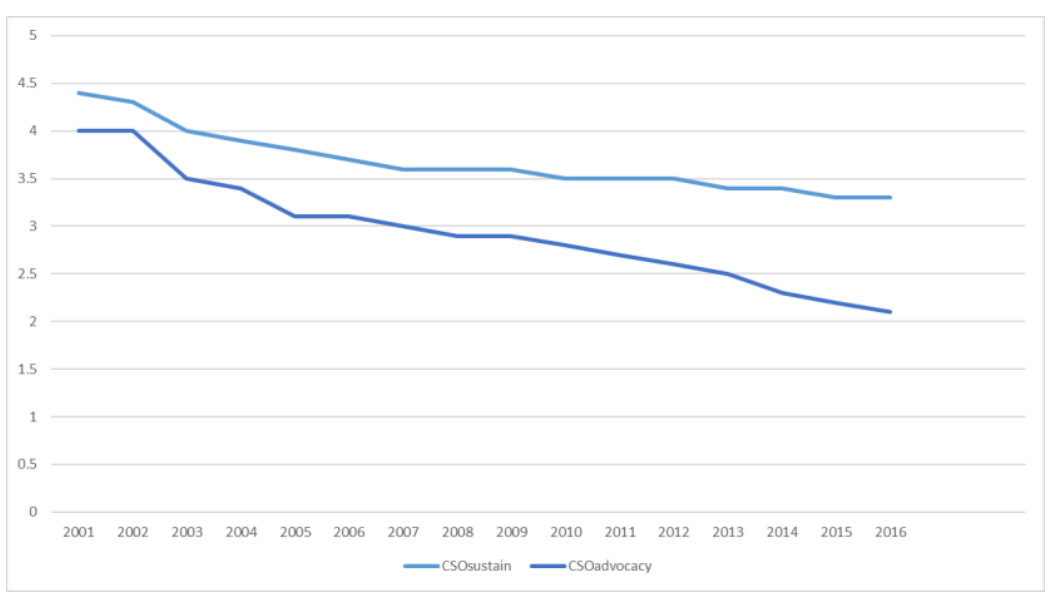

Figure 3: Civil Society Strength 


\section{Correlations}

Table 1. Pairwise Correlations featuring civil society strength indicators

\begin{tabular}{|c|c|c|c|c|c|c|c|c|c|c|c|}
\hline & & & & & & & & & & TrustRada & LawAgencies \\
\hline \multirow[t]{9}{*}{ Kendall's tau_b } & \multirow[t]{3}{*}{ CS } & Correlation Coefficient & 1.000 & -.823 & -.814 & .253 & .008 & .342 & .332 & -.205 & $-.730^{\star \star}$ \\
\hline & & Sig. (2-tailed) & . & .000 & .000 & .186 & .964 & .070 & .077 & .277 & .000 \\
\hline & & $\mathrm{N}$ & 16 & 16 & 16 & 16 & 16 & 16 & 16 & 16 & 16 \\
\hline & \multirow[t]{3}{*}{ Csosustain } & Correlation Coefficient & $-.823^{\mathrm{kx}}$ & 1.000 & $.970^{* \star}$ & $-.459^{\star}$ & .035 & $-.458^{\star}$ & $-.386^{\star}$ & .167 & $.743^{* \star}$ \\
\hline & & Sig. (2-tailed) & .000 & . & .000 & .019 & .855 & .018 & .045 & .385 & .000 \\
\hline & & $\mathrm{N}$ & 16 & 16 & 16 & 16 & 16 & 16 & 16 & 16 & 16 \\
\hline & \multirow[t]{3}{*}{ CSOadvocacy } & Correlation Coefficient & $-.814^{\mathrm{x}}$ & $.970^{\pi \star}$ & 1.000 & $-.432^{x}$ & .077 & $-.397^{\star}$ & -.369 & .190 & $.762^{\star *}$ \\
\hline & & Sig. (2-tailed) & .000 & .000 & . & .025 & .684 & .037 & .051 & .318 & .000 \\
\hline & & $\mathrm{N}$ & 16 & 16 & 16 & 16 & 16 & 16 & 16 & 16 & 16 \\
\hline
\end{tabular}

EU Aid and Perceptions of Corruption. Figures 5 and 6 depict indices of corruption trending in a positive direction, which means perceptions of corruption have decreased. This positive trend, and CS aid's positive, though non-normal, trend indicates a somewhat monotonic relationship. A Kendall's tau-b correlation was run to determine the relationship between these two variables, and there was a very weak correlation between CS aid and both corruption perception indicators, neither of which were statistically significant at the .05 level (two-tailed) $\left(\mathrm{CPI} \tau_{\mathrm{b}}=.253, p=.186 ; \mathrm{CoC} \tau_{\mathrm{b}}=.008, p=.964\right)$. In the pairwise correlations, several other variables, including CSOsustain, CSOadvocacy, and TrustCSO, had somewhat stronger relationships with the corruption indicators, and thus are likely better predictive variables. As such, Hypothesis 2 cannot be substantiated.

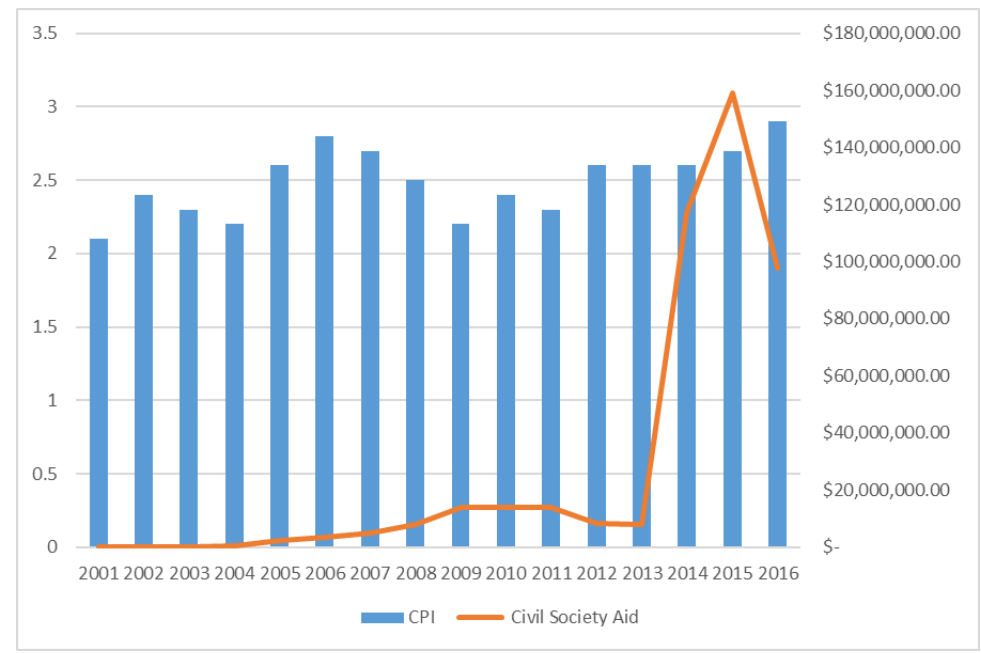

Figure 5: Corruption Perception Index 


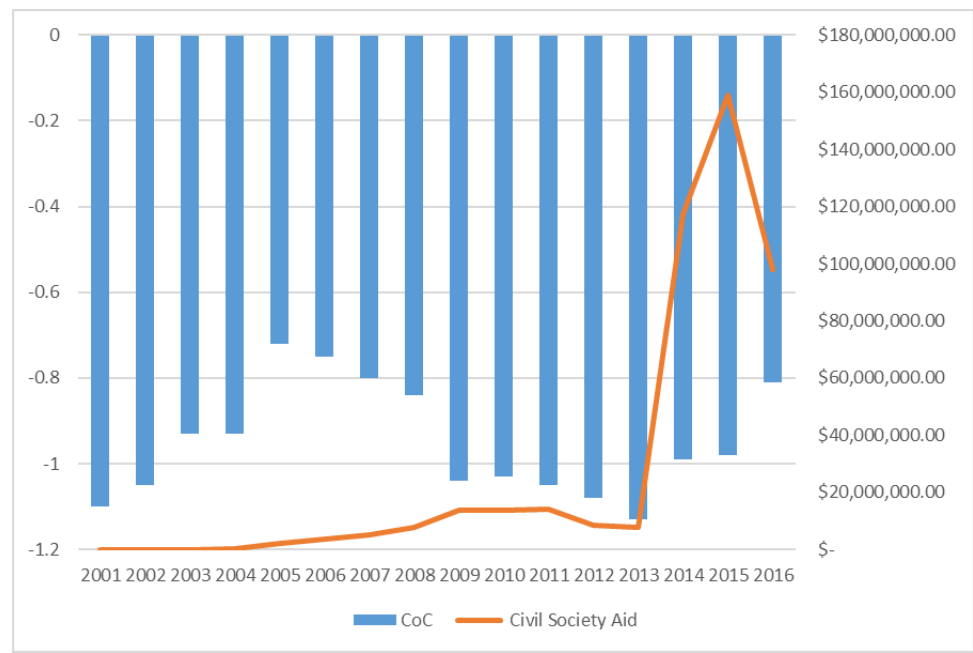

Figure 6: Control of Corruption

Table 2. Pairwise Correlations featuring corruption indicators

\begin{tabular}{|c|c|c|c|c|c|c|c|c|c|c|c|}
\hline \multicolumn{12}{|c|}{ Correlations } \\
\hline & & & CS & $\mathrm{CPI}$ & $\mathrm{CoC}$ & CSOsustain & CSOadvocacy & TrustcSOs & $\begin{array}{c}\text { TrustCityCou } \\
\text { ncil }\end{array}$ & TrustRada & LawAgencies \\
\hline \multirow[t]{9}{*}{ Kendall's tau_b } & \multirow[t]{3}{*}{ CS } & Correlation Coefficient & 1.000 & .253 & .008 & $-.823^{\prime \prime}$ & $-.814^{N *}$ & .342 & .332 & -.205 & $-.730^{\mathrm{m}}$ \\
\hline & & Sig. (2-tailed) & . & .186 & .964 & .000 & .000 & .070 & .077 & .277 & .000 \\
\hline & & $\mathrm{N}$ & 16 & 16 & 16 & 16 & 16 & 16 & 16 & 16 & 16 \\
\hline & \multirow[t]{3}{*}{$\mathrm{CPI}$} & Correlation Coefficient & .253 & 1.000 & .351 & $-.459^{*}$ & $-.432^{*}$ & $.471^{\circ}$ & $.390^{*}$ & .222 & -.313 \\
\hline & & Sig. (2-tailed) & .186 & . & .068 & .019 & .025 & .015 & .044 & .252 & .108 \\
\hline & & $\mathrm{N}$ & 16 & 16 & 16 & 16 & 16 & 16 & 16 & 16 & 16 \\
\hline & \multirow[t]{3}{*}{$\mathrm{CoC}$} & Correlation Coefficient & .008 & .351 & 1.000 & .035 & .077 & .283 & .034 & .283 & .086 \\
\hline & & Sig. (2-tailed) & .964 & .068 & . & .855 & .684 & .135 & .856 & .134 & .650 \\
\hline & & $\mathrm{N}$ & 16 & 16 & 16 & 16 & 16 & 16 & 16 & 16 & 16 \\
\hline
\end{tabular}

EU Aid and Social Trust. Figure 8 shows that trust in local city councils, a form of local government, and CSOs, increased over time with only moderate volatility. In context of the collective action problem, the positive trend of these variables is good since increased trust frequently occurs simultaneously with reduced corruption. To test the relationship between the generalized trust indicators and CS aid, a Kendall's tau-b correlation was run, and there was a weak to moderate correlation between CS aid the generalized trust indicators, neither of which wre statistically significant at the .05 level (two-tailed) (TrustCSOs $\tau_{\mathrm{b}}=.342, p=.07$; TrustCityCouncils $\tau_{\mathrm{b}}=.332, p=.077$ ). The pairwise correlations show that both generalized trust indicators are more strongly correlated with CPI, CSOsustain, and CSOadvocacy, especially the TrustCSOs variable. This analysis partially supports Hypothesis 3.1 - that EU aid targeted at civil society may marginally increase levels of generalized societal trust. However, other 
variables, such as strength of civil society and perceptions of corruption, may be more powerful predictors of generalized trust.

In Figure 9, trust in the Verkhovna Rada, Ukraine's parliament, and law agencies, are somewhat more volatile variables and remain at depressingly low percentages, and these low percentages do not bode well for a legitimate and effective government. To see if CS aid contributes to these low numbers, a Kendall's tau-b correlation found a weak correlation between CS aid and trust in the parliament, but a strong, negative, and significant (at the .05 level twosided) correlation between CS aid and trust in law agencies (TrustRada $\tau_{\mathrm{b}}=-.205, p=.277$; TrustLawAgencies $\left.\tau_{\mathrm{b}}=-.73, p=.000\right)$. The pairwise correlations show no stronger correlation for trust in the parliament, but do show an equally strong correlation between TrustLawAgencies and the civil society strength indicators, thus positing that those variables are better predictors yet again. This analysis shows that EU aid likely does not affect perceptions of the parliament, but it may affect levels of trust for law agencies, perhaps because most civil society projects supported by the EU are focused on the judicial system. Unfortunately, the few factors in this analysis somewhat support Hypothesis 3.2 - that EU aid may marginally increase levels of distrust in the governmental institutions.

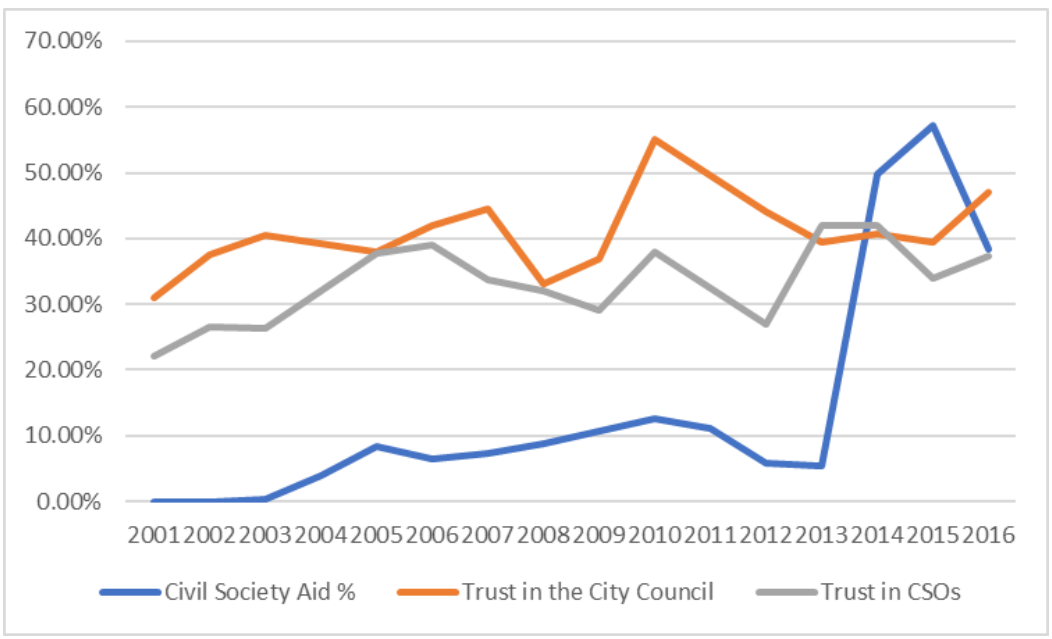

Figure 8: Generalized Social Trust 




Figure 9: Trust in Governmental Institutions

Table 3. Pairwise Correlations featuring levels of trust

\begin{tabular}{|c|c|c|c|c|c|c|c|c|c|c|c|}
\hline \multicolumn{12}{|c|}{ Correlations } \\
\hline & & & CS & TrustCSOs & $\begin{array}{l}\text { TrustCityCou } \\
\text { ncil }\end{array}$ & TrustRada & $\begin{array}{l}\text { TrustLawAge } \\
\text { ncies }\end{array}$ & $\mathrm{CPI}$ & $\mathrm{CoC}$ & CSOsustain & CSOadvocacy \\
\hline \multirow[t]{15}{*}{ Kendall's tau_b } & \multirow[t]{3}{*}{ CS } & Correlation Coefficient & 1.000 & .342 & .332 & -.205 & $-.730^{\mathrm{Nm}}$ & .253 & .008 & $-.823^{\mathrm{km}}$ & $-.814^{\mathrm{m}}$ \\
\hline & & Sig. (2-tailed) & & .070 & .077 & .277 & .000 & .186 & .964 & .000 & .000 \\
\hline & & $\mathrm{N}$ & 16 & 16 & 16 & 16 & 16 & 16 & 16 & 16 & 16 \\
\hline & \multirow[t]{3}{*}{ Trustcsos } & Correlation Coefficient & .342 & 1.000 & .303 & .278 & -.201 & $.471^{*}$ & .283 & $-.458^{\star}$ & $-.397^{*}$ \\
\hline & & Sig. (2-tailed) & .070 & . & .112 & .145 & .295 & .015 & .135 & .018 & .037 \\
\hline & & N & 16 & 16 & 16 & 16 & 16 & 16 & 16 & 16 & 16 \\
\hline & \multirow[t]{3}{*}{ TrustCityCouncil } & Correlation Coefficient & .332 & .303 & 1.000 & .130 & -.209 & $.390^{*}$ & .034 & $-.386^{*}$ & -.369 \\
\hline & & Sig. (2-tailed) & .077 & .112 & . & .495 & .274 & .044 & .856 & .045 & .051 \\
\hline & & $\mathrm{N}$ & 16 & 16 & 16 & 16 & 16 & 16 & 16 & 16 & 16 \\
\hline & \multirow[t]{3}{*}{ TrustRada } & Correlation Coefficient & -.205 & .278 & .130 & 1.000 & .358 & .222 & .283 & .167 & .190 \\
\hline & & Sig. (2-tailed) & .277 & .145 & .495 & . & .062 & .252 & .134 & .385 & .318 \\
\hline & & N & 16 & 16 & 16 & 16 & 16 & 16 & 16 & 16 & 16 \\
\hline & \multirow[t]{3}{*}{ TrustLawAgencies } & Correlation Coefficient & $-.730^{\star *}$ & -.201 & -.209 & .358 & 1.000 & -.313 & .086 & $.743^{\mathrm{*m}}$ & $.762^{\mathrm{x}}$ \\
\hline & & Sig. (2-tailed) & .000 & .295 & .274 & .062 & . & .108 & .650 & .000 & .000 \\
\hline & & N & 16 & 16 & 16 & 16 & 16 & 16 & 16 & 16 & 16 \\
\hline
\end{tabular}

\section{Conclusion}

Obviously, the relationship between corruption, civil society, and international aid is complex, non-linear, and affected by a host of intervening variables, especially in the context of Ukraine's turbulent history, current politically instability, and border conflict. Additionally, the lack of consistent, comprehensive aid and sociological data in the field made a rigorous regression analysis of this topic difficult. However, with the available data, this research has come to several conclusions, both qualitatively and quantitatively.

The qualitative review of the literature and the context of Ukraine suggests that civil society anti-corruption measures could balance empowering the state and reforming it. Strengthening 
civil society should create communal bonds through civic activity that would improve generalized social trust, thus combating the culture of corruption. Additionally, an engaged civil society can apply pressure on the government to pass reforms and keep it accountable, thus reducing corruption.

Quantitatively, several observations can be made as regards the interaction between the variables of interest. For Hypothesis 1, it is possible that EU aid targeted at civil society has strengthened Ukraine's civil society, as this hypothesis has the strongest statistically determined relationship. For Hypothesis 2, CS aid does not appear to directly correlate with corruption perceptions, which could be explained by the faulty nature of these indicators or simply a lack of predictive power in the CS aid variable. Lastly, for Hypotheses 3.1 and 3.2, while there was not relationship between trust in the parliament and CS aid, there was a significant correlation between CS aid and trust in law agencies, where more CS aid meant less trust in law agencies, indicating certain unintended consequences.

When accounting for the pairwise correlations in context of this research, the civil society strength indicators in general correlated most strongly with all the other variables, indicating that civil society is indeed related to levels of social trust and corruption in some fashion as the literature highlighting a collective action problem and the importance of social accountability suggest. Even if the effects of EU aid on corruption and trust were nominal in this analysis, its apparent, positive, relationship with the strength of civil society, and the strength of civil society's strong, potentially predictive relationship with the other variables, could indicate that EU civil society aid is indirectly influencing levels of corruption and social trust.

To confirm these hypotheses, and develop more statistically reliable results, more data and more time will be necessary. Steps to improve this involve both researchers and practitioners. Corruption and civil society's conceptual haziness makes data and indicator collection difficult. More consistent definitions by all actors could improve this dilemma. Additionally, increasing the amount of accessible data, particularly by the EU, would be tremendously helpful. If these steps are taken, this field could be able to better identify specific determinants and solutions to the problem of corruption and collective action in Ukraine. 


\section{References}

Andersson, S., \& Heywood, P. M. (2006). Anti-corruption as a risk to democracy: on the unintended consequences of international anti-corruption campaigns. In L. Sousa, P. Larmour, and B. Hindess. (Eds.), Governments, NGOs and Anti-Corruption (pp. 33-50). Retrieved From: https://www.taylorfrancis .com/books/e/9781134035465

Bhargava, V., Cutler, K., Ritchie, D. (2011). Stimulating the Demand for Good Governance. Retrieved from the Partnership for Transparency website: https://ppp.worldbank.org/public-privatepartnership/sites/ppp.worldbank.org/files/documents/World\%20Bank_stimulating\%20demand\%2 Ofor\%20good\%20governance_EN.pdf

European External Action Service. (2019). EU-Ukraine relations, factsheet. Retrieved from https://eeas. europa.eu/headquarters/headquarters-homepage_en/4081/\%20EUUkraine\%20relations, \%20factsheet

International Aid Transparency Initiative, (n.d.). IATI Datastore CSV Query Builder. Retrieved from http://datastore.iatistandard.org/query/

Kiev International Institute of Sociology (2015). Corruption in Ukraine. Retrieved from https: //kiis.com.ua/materials/pr/20161602_corruption/Corruption\%20in\%20Ukraine\%202015\%20ENG .pdf

Laerd Statistics. (2018). Kendall's Tau-b using SPSS Statistics. Retrieved from https://statistics.laerd.com/spss-tutorials/kendalls-tau-b-using-spss-statistics.php

Letki, N, \& Evans, G. (2005, July). Endogenizing Social Trust: Democratization in East-Central Europe. British Journal of Political Science, 35, 515-529. doi: 10.1017/S000712340500027X

Marín, J. M. (2016, January). Evidence of citizen engagement impact in promoting good governance and anti-corruption efforts. Retrieved from U4 Anti-Corruption Resource Center website: https://www.u4.no/publications/evidence-of-citizen-engagement-impact-in-promoting-goodgovernance-and-anti-corruption-efforts.pdf

Mungiu-Pippidi, A. (2013, January). Controlling Corruption Through Collective Action. Journal of Democracy, 24, 101-115. Retrieved from https://www.journalofdemocracy.org/article/controlling-corruption-through-collective-action

Schmidt, D. (2007). Anti-Corruption: What Do We Know? Research on Preventing Corruption in the Post-communist World. Political Studies Review, 5, 202-232. doi: 10.1111/j.14789299.2007.00129.x

Transparency International. Corruption Perceptions Index. Retrieved from https://www.transparency.org/research/cpi/overview

UK Department for International Development (DFID) (2015, January). Why corruption matters: understanding causes effects and how to address them (Evidence paper on corruption). Retrieved from https://assets.publishing.service.gov.uk/government/uploads/system/uploads/attachment _data/file/406346/corruption-evidence-paper-why-corruption-matters.pdf 
Wolczuk, K., \& Žeruolis, D. (2018, August). Rebuilding Ukraine: An Assessment of EU Assistance. Retrieved from publications on Chatham House website: https://www.chathamhouse.org/sites/ default/files/publications/research/2018-08-16-rebuilding-ukraine-eu-assistance-wolczukzeruolis.pdf

Zapata, M. (2018, August). Collective Action Theory Applied to Anti-Corruption Practice: A Bolivian Case Study (Research Paper Series No. 07). Retrieved from International Anti-Corruption Academy website:

https://www.iaca.int/images/Research/Research_Paper_07_Martin_Zapata_final.pdf 